\title{
Housing Development Building Management System (HDBMS) For Optimized Electricity Bills
}

\author{
Weixian $\mathrm{Li}^{*}$, Thillainathan Logenthiran ${ }^{\dagger}$, Van-Tung Phan ${ }^{\llbracket}$, and Wai Lok Woo" \\ School of Electrical and Electronic Engineering, Newcastle University, Singapore Campus ${ }^{* \dagger} \ddagger \S \rrbracket \|$ \\ Email: *w.li17@newcastle.ac.uk, †t.logenthiran@ncl.ac.uk, `,vantung.phan@ncl.ac.uk, "lok.woo@newcastle.ac.uk
}

\begin{abstract}
Smart Buildings is a modern building that allows residents to have sustainable comfort with high efficiency of electricity usage. These objectives could be achieved by applying appropriate, capable optimization algorithms and techniques. This paper presents a Housing Development Building Management System (HDBMS) strategy inspired by Building Energy Management System (BEMS) concept that will integrate with smart buildings using Supply Side Management (SSM) and Demand Side Management (DSM) System. HDBMS is a MultiAgent System (MAS) based decentralized decision making system proposed by various authors. MAS based HDBMS was created using JAVA on a IEEE FIPA compliant multi-agent platform named JADE. It allows agents to communicate, interact and negotiate with energy supply and demand of the smart buildings to provide the optimal energy usage and minimal electricity costs. This results in reducing the load of the power distribution system in smart buildings which simulation studies has shown the potential of proposed HDBMS strategy to provide the optimal solution for smart building energy management.
\end{abstract}

Index Terms-Power distribution system, Smart Buildings, Multi-agent system, Demand side management, Supply side management, Building energy management system, Housing development building management system, Electricity bills

\section{INTRODUCTION}

Electricity has become a basic necessity for modern society and is a vital part of a socio-economic development in the world. The common challenges faced by the electricity suppliers would be systems constraints and administrative issues while supplying electricity. Additionally, past studies had shown a steady increase in annual electricity demand through the past few years due to consumers needs with respect to comfort, convenience and flexibility. In order to meet the growing demand of electricity, solutions from grid distribution to end users are required [1].

Smart grid represents a innovative next generation of power system network that delivers power from supply to demand. It uses a two-way communications which leads to enhanced reliability and energy efficiency of the grid. It has the capabilities of sensing grid situations, measure power and control appliances to electricity generations, transmission and distribution of the power grid. This increased the number of decentralised renewable energy sources due to increasing electricity demand. These issues created challenges for a stable and secure operation of power grid. Major developments were based on traditional electrical system planning and operations with information and communications technology [2]. This concept of intelligent power grid performs independent adaptations of its elements for optimal electricity consumption [3].
Important elements of a smart grid includes demand response, load management and customer engagement. The accuracy of forecasting supply and demand depends on smart meters. The stability of grid in Singapore has one of the most reliable electricity networks in the world. Singapore grid has already deployed advanced Supervisory Control and Data Acquisition (SCADA) systems with two-way communication channels. This situation creates an ideal place to bring new technologies to enhance the capability of its power grid. With the help of advanced technologies, the grid was able to respond efficiently and effectively to power disruptions [4].

Building Energy Managements System is a part of a smart grid system that control, monitor and optimize energy for buildings. BEMS play a critical role in achieving overall energy efficiency by reducing carbon footprints. As it is a key requirement for designing modern buildings and industries. Technology improvement on control systems, energy managements systems, distributed decision making and coordination for buildings contribute to better efficiency of energy usage [5].

In modern times, BEMS considered improvement on energy utilization efficiency, reduction of energy cost and integration of renewable energy technology. These improvements was meant to meet the energy demand of the buildings. To align with the zero-energy objectives and intelligent building concepts, BEMS aims to increase energy efficiency by integrating Demand Side Management and Supply Side Management. These functions decreases energy cost and sustain consumer comforts by optimizing buildings electrical distribution. It will solve complex issues through coordination and cooperation of the management systems. This is due to the system being flexible, reliable and efficient [6].

Supply Side Management (SSM) was identified as a method of optimizing the electrical supplies from various power sources. One of the key issues for future energy distribution systems, smart buildings and smart devices was the need of an intelligent management of energy distributions. The problem can be tackled from the supply sources on how electricity should be distributed. It helps to improve electrical efficiency by developing an optimal algorithm for the system. Thus, electricity can be used in an efficient manner [7], [8].

Demand Side Management (DSM) was identified as a method of optimizing energy demand consumption to achieve better efficiency and operations in an electrical system. DSM usually involves demand response and peak load scheduling. As electricity was cheaper during night time due to the whole- 
sale electricity market. This encourages consumers to use more electricity during these periods, thus reducing electricity costs for end consumers [9].

Due to limitations of centralised computing capabilities on large scale power distribution system, it made decentralised and semi-centralised decision making procedures desirable in electrical distribution systems. One of the promising communication systems in solving multiple objectives during optimal period for distribution systems was the Multi-Agent Systems (MAS). MAS focuses on artificial intelligence agent interactions to solve issues and provide improvement on technologies [10].

Multi-Agent system is a system that comprises of two or more intelligent agents that cooperates, coordinates and negotiates to achieve its goal and objectives. It was designed to solve complex problems using the best solution available. Generally, an agent based system is usually formed by two agents either software or hardware. It will react to changes within its own environment. It is designed and based on its reactivity, pro-activeness and social ability in the environment. In order to ensure that agents were organized in a hierarchical structure, several agents were given authority to overwrite other agents decision in a logical manner. However, a decentralized decision system permit agents to have their own decision making unless the solution was deemed unsatisfactory [11]-[14].

Java Agent DEvelopment Framework (JADE) is a java extension based software framework available for Multi-Agent System (MAS) development. This framework complies with IEEE FIPA standards. MAS implementation through a middle ware, requires a minimum system of the JAVA (the runtime environment or the JDK) version 5 is needed to execute within a Java Virtual Machine (JVM) [15], [16].

In this paper, Housing Development Building Management System (HDBMS) using BEMS concept on residential building was developed [17].Its ability to optimize the electricity distribution and lower consumers electricity cost will be discussed. The distribution management of HDBMS uses decision-making of Multi-agent Systems for electricity distribution with the objective of decreasing electrical cost, improve energy efficiency and optimize residents comfort.

The remaining paper is organized as follows: Section II shows the information for Singapore smart building. Section III shares the methodology for the House Development Building Management System (HDBMS). Section IV explains the proposed MAS architecture for smart HDBMS. Section $\mathrm{V}$ provides simulation results and discussed in section VI. Finally, the paper is concluded in the section VII.

\section{INFORMATION ABOUT SINGAPORE RESIDENTIAL BUILDING}

\section{A. Housing Development Board (HDB) Buildings}

Fig. 1 shows the percentage of how electricity is distributed in Singapore in 2014. This chart allows understanding of the amount of electricity being distributed to various sectors in Singapore [18]. Residential Buildings contributes to $15 \%$ of the total electricity consumption which was $6.936 \mathrm{GWh}$ by households in Singapore.
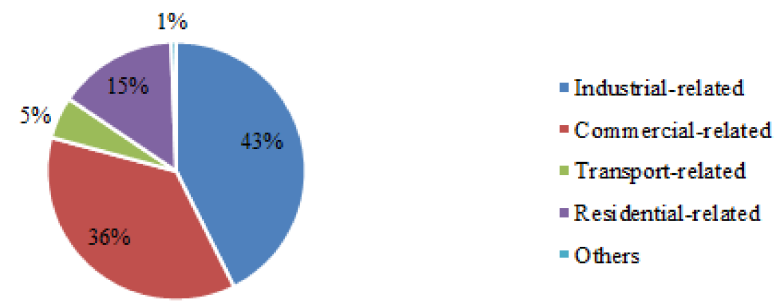

Fig. 1. Distribution of Singapore Electricity

Fig.2 shows the percentage of electricity distributed in the residential sectors for year 2014 [3]. The chart shows $60 \%$ of the electricity were distributed to public housing. It consists mainly Housing Development Board (HDB) Buildings in Singapore, therefore it is essential to find alternatives in this area to have better energy efficiency.

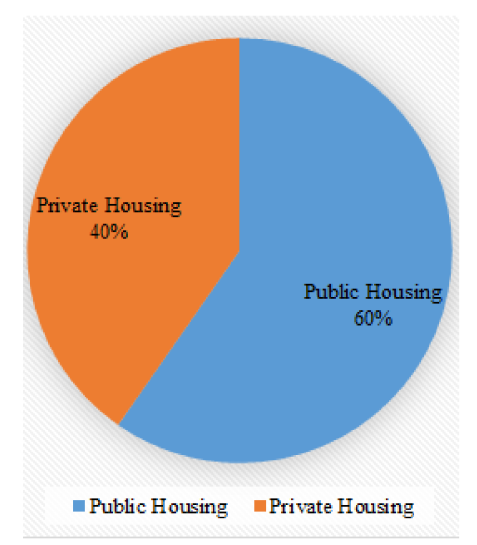

Fig. 2. Singapore residential electricity consumption in 2014

Fig.3 shows a concept of a potential Singapore smart grid concept that will be created in the future. Smart Grid concept was introduced to provide a two-way communication for consumers supply and demand of electricity. Major developments were based on traditional electrical system planning and operations with information and communications technology [4].

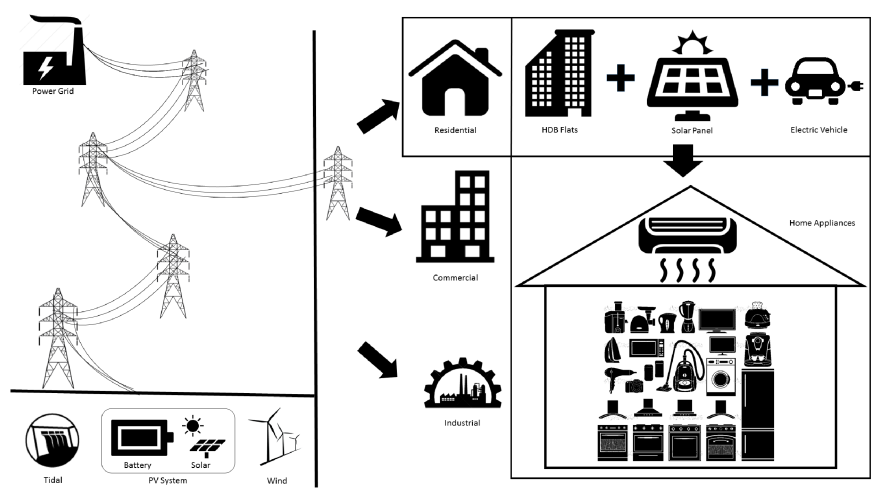

Fig. 3. Illustration of Singapore smart grid concept

Fig. 4 shows the average monthly electricity consumption by public and private housing in Singapore for 2014. The average 
monthly electricity consumption by public housing unit was $371 \mathrm{kWh}$ [19].

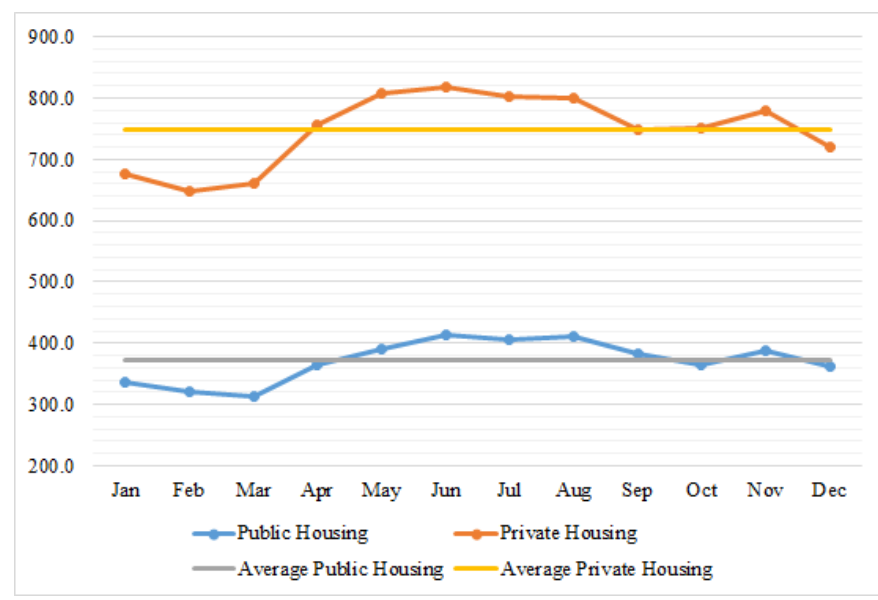

Fig. 4. Residential Average Monthly Electricity Consumption in 2014

The power utilization of frameworks, for example, regular territory lighting, lifts and water pumps of a normal HDB residential building was estimated to be $75,000 \mathrm{kWh}$ a year [20].

According to a research done in 2015, the public housing buildings known as Housing and Development Board (HDB) blocks currently has 9503. This indicated that there were 980108 units of flats which averaged to 103 units per block [21]. This information builds a realistic situation for the experiment.

\section{B. Singapore Electricity Prices}

Following 2001, the Energy Market Authority (EMA) opened a retail electricity market to give consumers options to manage their energy cost through the competition of different providers. Instead of buying at regulated electricity tariff which is known as non-contestable price from SP Services Limited (SPS). Consumers were able to purchase electricity from electricity retailers or wholesale electricity market at prices that varies every half-hour which is known as contestable prices.

In order to switch to contestable prices, consumers with an average electricity consumption of $2000 \mathrm{kWh}$ per month were eligible for the scheme [22].

The non-contestable consumers pricing will be 20.35 cents per $\mathrm{kWh}$ (with effect from 1 Oct 15 to 31 Dec 15) regardless of the time periods [23].

Data collected were used for accommodation of different pricing that allows research on whether power delivered from a contestable or non-contestable electricity source be more economical for residential building in Singapore.

Fig. 5 shows the price for a Contestable consumer in a 48 period format. It represents a day where each period is half an hour from Energy Market Company (EMC) for 1 September 2015 [24].

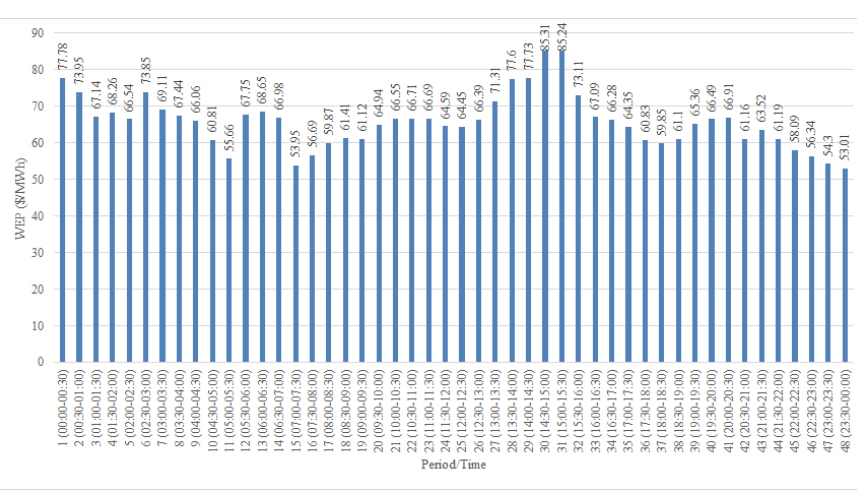

Fig. 5. Wholesale Pricing used for 48 periods

\section{Singapore Photovoltaics (PV) System}

The capability of PV electricity generation in Singapore depends essentially on the space and the efficiency of the PV systems. The annual electricity demand in Singapore is $42 \mathrm{TWh}$ in 2011; the total installed solar PV capacity was $4 \mathrm{MWp}$ for both residential and non-residential installation which generates about $4.8 \mathrm{GWh}$ per annum [25]. The PV system was able to yield $51 \mathrm{kWh}$ per day between $0700-1900$ hours in Singapore.

\section{Singapore Electric Vehicle (EV)}

Table I shows the type of chargers available in Singapore. Public Normal Chargers and Residential Normal chargers are two types of commonly used chargers.

TABLE I

SINGAPORE TYPES OF CHARGERS

\begin{tabular}{|l|c|c|}
\hline Types of Charging Infrastructure & Electrical Power & Recharging Time \\
\cline { 1 - 1 } Public Normal Charger & $3 \mathrm{~kW}$ & $7-8$ hours \\
\cline { 1 - 1 } Residential Normal Charger & $30-50 \mathrm{~kW}$ & $30-45 \mathrm{~min}$ \\
\hline Quick Charger &
\end{tabular}

Public Normal Chargers are typically introduced or accessible at shopping centers, HDB car parks, and charging stations while Residential Normal Chargers were found in private properties. Both sorts of chargers have a more extended charging time of 7 to 8 hours in contrast to quick chargers.

The quick chargers are typically introduced or accessible at certain shopping centers and charging stations. It takes a quicker charging rate of 30 to 45 minutes as it will provide more electrical power.

For Electric Vehicle (EV) or hybrid car, charging stations are expected to energize the batteries for the vehicles which are about $24 \mathrm{~kW}$. There are presently 71 charging stations by Bosch in Singapore and buyers need to pay SGD\$180 a month for unlimited charging [26].

According to the Straits time, there are a total of approximate 1.25 million households and around $45 \%$ of households in Singapore own a car. [27].

The number of electrical vehicle in a residential building can be calculated by:

$$
C O_{\text {per } H D B \text { block }}=U_{\text {per } H D B \text { block }} * C O_{\text {percentage }}
$$


Where $C O_{\text {per } H D B}$ block represents the total Car Owners in a HDB block, $C O_{\text {percentage }}$ refers to the percentage of car owners, $U_{\text {per } H D B \text { block }}$ represents the number of units in a HDB block.

The total battery storage by EV can be calculated by:

$$
E V B S_{\text {per } H D B \text { block }}=C O_{\text {per } H D B \text { block }} * E V B S_{\text {per car }}
$$

Where $E V B S_{\text {per } H D B}$ block represents the total EV battery storage in a HDB block and $E V B S_{\text {per car }}$ for one EV battery storage.

The charging/discharging rate by the total number of EV battery storage can be calculated by:

$$
E V D C_{\text {per } H D B \text { block }}=C O_{\text {per } H D B \text { block }} * E V D C_{\text {per car }}
$$

Where $E V D C_{\text {per } H D B}$ block represents the total charging/discharging rate for a HDB block and $E V D C_{p e r}$ car is for one EV.

\section{Proposed Housing Development Building MANAGEMENT SYSTEM (HDBMS)}

Fig.6 shows the flowchart of the algorithm used for the calculation of HDBMS to provide the optimize results.

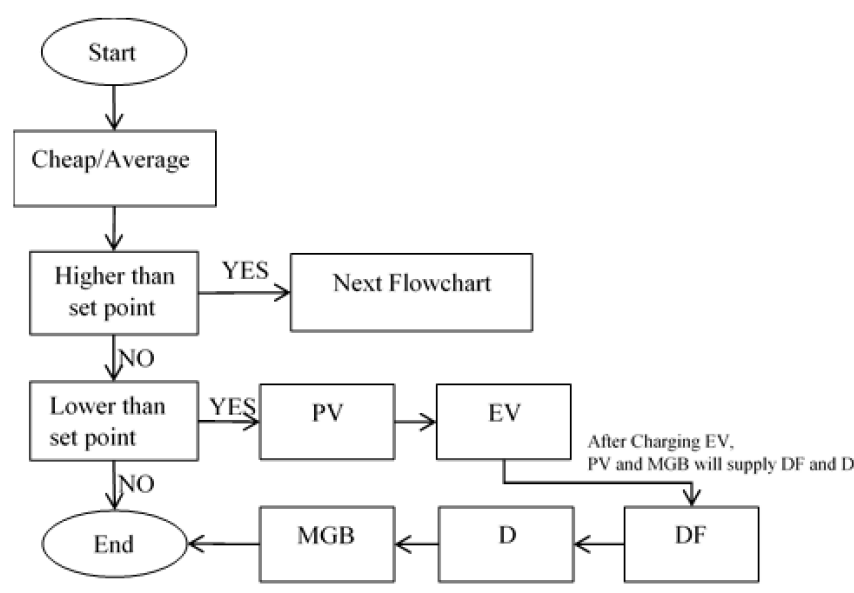

Fig. 6. Flowchart for HDBMS

There is two set points involve, one is using the average of the pricing and the other is using the cheaper range of the pricing.

When the price at that period is higher than set point, it will refer to Fig.6 to calculate the price for that period.

When the price at that period is lower than set point, it will buy the maximum charging rate of the EV batteries and the total demand for that period as the prices are lower. In this case, it is able to store the electricity at a cheaper rate and use it during the periods of higher price rate.

Fig.7 represents the flowchart when the period price is higher than the set point calculated.

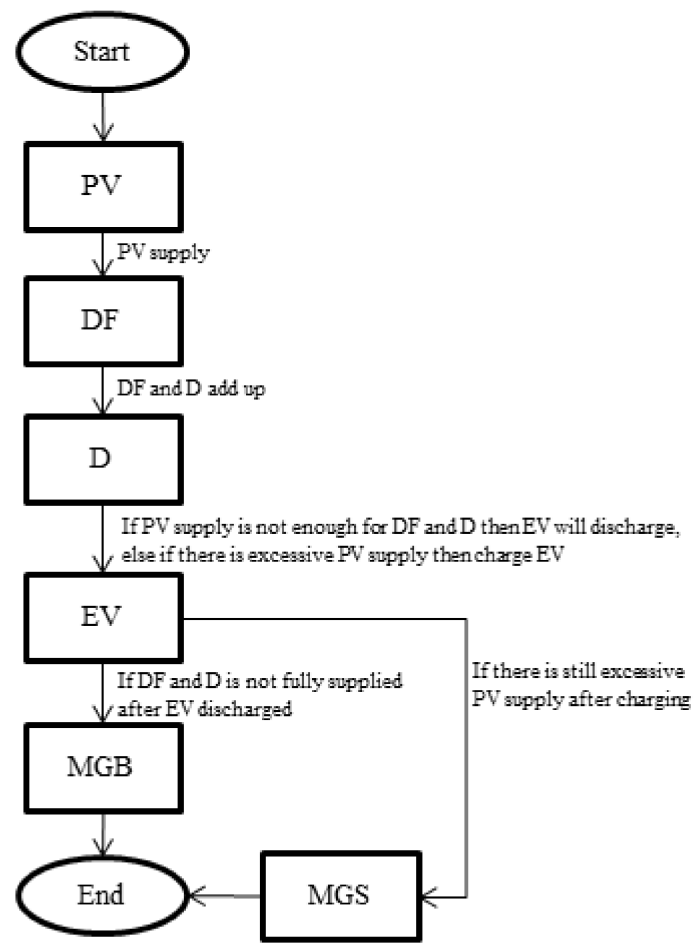

Fig. 7. Flowchart when set point is higher

The PV power will first supply to the demand of HDB building facilities like the lifts, lights and other electrical devices. It will then supply to the Demand of HDB units. After all the demand, extra PV power left will be stored in the EV batteries(Discharging, charging rate considered) and sold back to the grid.

If at any point that the PV power is not sufficient to supply the demand, it will use power from the EV batteries (Discharging, charging rate considered) and in event of insufficient power supplied, additional power will be supplies by the main grid.

Table II shows the representatives and description of Fig.6 and Fig.7. It explains the function for the following flowcharts.

TABLE II

\begin{tabular}{|c|c|c|}
\hline Name & Representative & Descriptions \\
\hline \multicolumn{3}{|c|}{ Block Representative } \\
\hline HDB units demand & $\mathrm{D}$ & Total electricity demand of HDB units \\
\hline HDB Building facilities demand & $\mathrm{DF}$ & Total electricity demand for HDB facilities \\
\hline Photovoltaics System & PV & Supply of solar power \\
\hline Electric Vehicle & EV & Battery storage \\
\hline Main Grid Buy & MGB & Buying electricity from Main grid \\
\hline Main Grid Sell & MGS & Selling electricity to Main Grid \\
\hline
\end{tabular}

REPRESENTATIVE AND DESCRIPTION FOR FIG.6 AND FIG.7

The following formulas has been implemented in the system as show in Fig. 6 and Fig.7.

The average set point calculation based on the contestable pricing can be calculated by:

$$
A v g P t_{\text {period }}=\left(\sum_{i=1}^{48} C P_{(i)}\right) / i
$$

Where $A v g P t_{\text {period }}$ represents the average set point for each period, $C P_{(i)}$ represents the total contestable pricing for a period and $i$ represent the period time. 
The cheap set point calculation based on the contestable pricing can be calculated by:

$$
\text { CheapPt }_{\text {period }}=C P_{i /(E V F S / E V D C / 2)}
$$

Where CheapPt $t_{\text {period }}$ represents the cheap set point for each period and $E V F S$ represents the electric vehicle full battery storage.

The contestable pricing without using set point method can be calculated by:

$$
C P_{d a y}=\left(\sum_{i=1}^{48} C P_{(i)} * P D_{(i)}\right)
$$

Where $C P_{d a y}$ represents the total contestable pricing for the day and $P D_{(i)}$ represents the total power demand for the period.

The non-contestable pricing without using set point method can be calculated by:

$$
N C P_{d a y}=\left(\sum_{i=1}^{48} N C P_{(i)} * P D_{(i)}\right)
$$

Where $N C P_{d a y}$ represents the total non-contestable pricing for the day and $N C P_{(i)}$ for a period.

\section{Proposed Multi-Agent System}

Fig.8 depicts the overall design of multi-agent system for Housing Development Building Management system (HDBMS). The functionality of SSM is to be in charge of data collection from the electrical supplies and calculate the total electricity it is able to supply. DSM function is to be in charge of collecting data from the electrical demand and calculate the total electricity required. HDBMS would then take the data from SSM and DSM to optimize the best solution for optimization of electricity prices

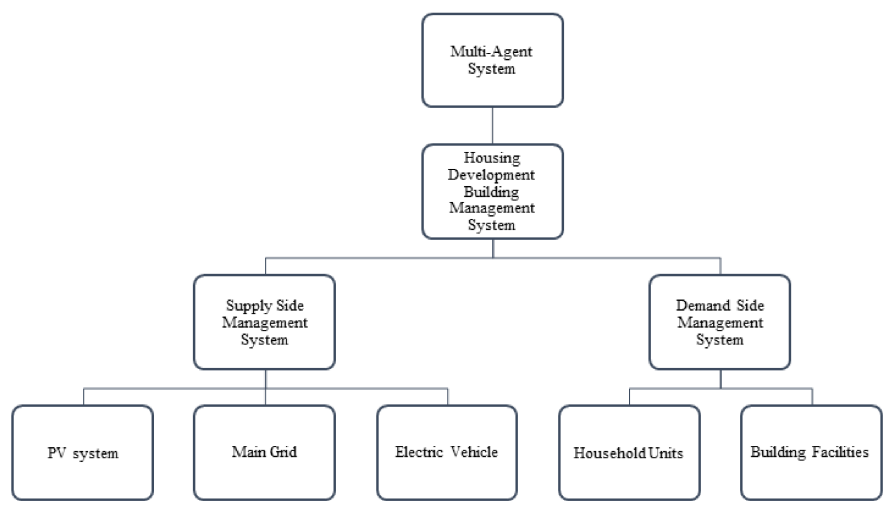

Fig. 8. Design of Multi-Agent System

Table III shows the representatives names used to program the multi-agent system. DSM manages the HDB Building demands. SSM manages the electrical supply systems. HDBMS manages the SSM and DSM requirements to make further decisions.

TABLE III

HDBMS AGENTS

\begin{tabular}{|c|c|c|}
\hline Name & Descriptions & Agent Representative \\
\hline $\begin{array}{c}|c| \\
\text { House Development Building } \\
\text { Management System }\end{array}$ & HDBMS & HDBMSAgent \\
\hline Demand Side Management & DSM & DSMAgent \\
\hline Supply Side Management & SSM & SSMAgent \\
\hline \multicolumn{2}{|c|}{ Electrical Supply System } \\
\hline Solar Panel & PV & PVSystemAgent \\
\hline Main Grid & MG & MGAgent \\
\hline Electric Vehicle & EV & EVAgent \\
\hline \multicolumn{2}{|c|}{ HDB Building demands } \\
\hline HDB Unit & HDBU & HDBUAgent \\
\hline HDB Facilities & HDBF & HDBFAgent \\
\hline
\end{tabular}

This allows the particular system to have a specific communication process or algorithms. It simplifies the coding procedures due to the hierarchy of the entire system. It benefits the control and manage programs to cater for the flexibility of altering the code due to an upgrade of the system when required.

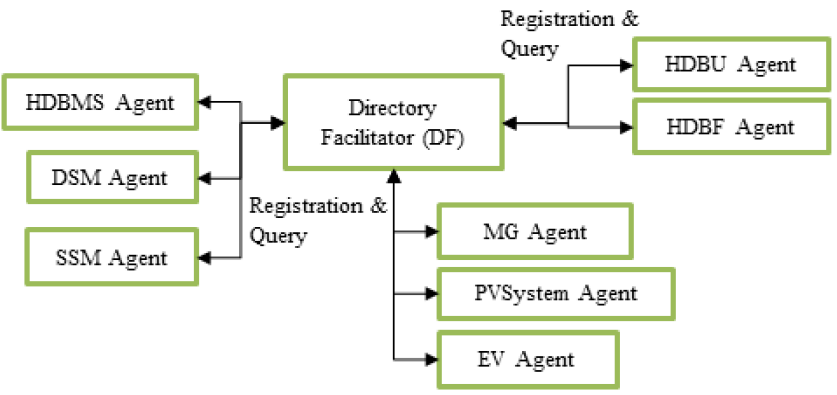

Fig. 9. Registration and query of agents

The Directory Facilitator (DF) was used to register and query the agents needed in the network as shown in Fig.9. This prevents the same agent to be recreated.

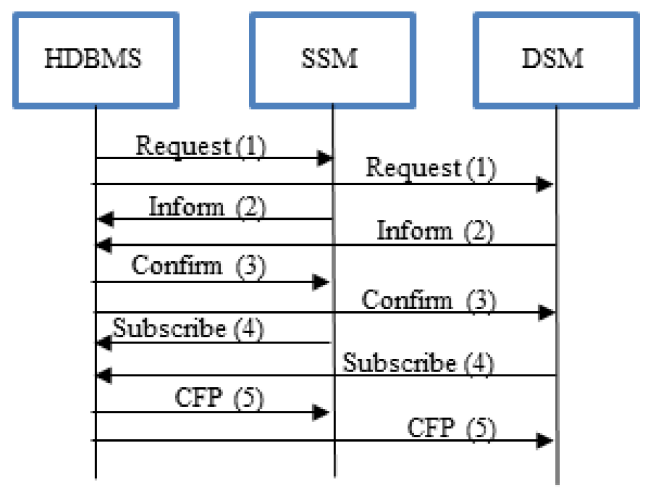

Fig. 10. HDBMS agents interactions

Fig.10 depicts the overall structure of the multi-agent system. Home Development Building Management System (HDBMS) was categorized into two parts which are the Supply 
Side Management (SSM) and Demand Side Management (DSM).

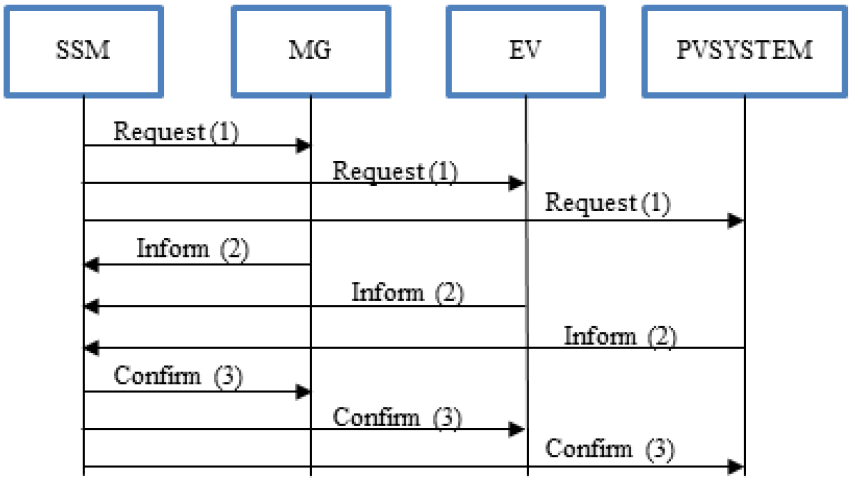

Fig. 11. SSM agents interaction

As shown in Fig.11, the functionality of SSM was in charge of data collection from the electrical supplies and calculates the total electricity supply.

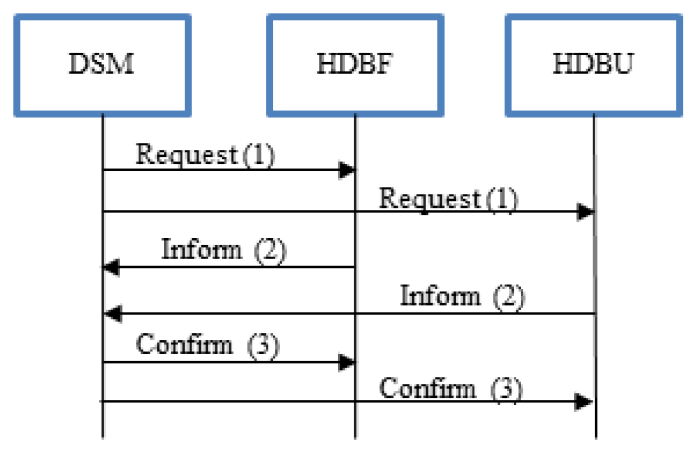

Fig. 12. DSM agents interaction

As shown in Fig.12, DSM function was in charge of collecting data from the electrical demand and calculate the total electricity required.

As multi-agent system were used to provide the communications, these figures shows the type of messages created to facilitate the communications between agents. The messages set were REQUEST, SUBSCRIBE, CONFIRM , INFORM and CFP. Each message sent provides different data messages when it is required during the process of algorithm calculations.

\section{Simulation AND Results}

\section{A. Housing Development Building Management System (HDBMS) results}

This sections shows the algorithm implementation results for Housing Development Building Management System (HDBMS).

Table IV shows the results from different simulations based on the duration. These are the simulation results for contestable pricing with no method, non-contestable pricing with no method, average set point system pricing and cheap set point system pricing were implemented for household consumers.
TABLE IV

SIMULATION RESULTS FOR DIFFERENT METHODS

\begin{tabular}{|c|c|c|c|c|}
\hline No. & $\begin{array}{c}\text { HDB non- } \\
\text { contestable } \\
\text { price }\end{array}$ & $\begin{array}{c}\text { HDB } \\
\text { contestable } \\
\text { price }\end{array}$ & $\begin{array}{c}\text { Using Average } \\
\text { as a set point }\end{array}$ & $\begin{array}{c}\text { Using Cheap } \\
\text { as a set point }\end{array}$ \\
\hline \multicolumn{5}{|c|}{ Year } \\
\hline $\mathbf{1}$ & $\$ 88,330.19$ & $\$ 28,555.82$ & $\$ 27,665.90$ & $\$ 25,135.81$ \\
\hline \multicolumn{5}{|c|}{ Months } \\
\hline $\mathbf{1}$ & $\$ 7,360.85$ & $\$ 2,379.65$ & $\$ 2,364.64$ & $\$ 2,142.51$ \\
\hline $\mathbf{2}$ & $\$ 7,360.85$ & $\$ 2,379.65$ & $\$ 2,300.11$ & $\$ 2,101.92$ \\
\hline $\mathbf{3 - 1 2}$ & $\$ 7,360.85$ & $\$ 2,379.65$ & $\$ 2,300.11$ & $\$ 2,089.14$ \\
\hline \multicolumn{5}{|c|}{ Days } \\
\hline $\mathbf{1}$ & $\$ 245.36$ & $\$ 79.32$ & $\$ 140.79$ & $\$ 92.08$ \\
\hline $\mathbf{2}$ & $\$ 245.36$ & $\$ 79.32$ & $\$ 77.07$ & $\$ 70.70$ \\
\hline $\mathbf{3 - 3 0}$ & $\$ 245.36$ & $\$ 79.32$ & $\$ 76.67$ & $\$ 70.70$ \\
\hline
\end{tabular}

Table V shows the per period results for average set point. It shows detail of the average set point pricing for each periods.

TABLE V

SiMULATION RESULTS FOR PERIODS USING AVERAGE SETPOINT

\begin{tabular}{|c|c|c|c|}
\hline \multicolumn{4}{|c|}{ Using Average as a set point } \\
\hline Period & Day 1 & Day 2 & Day 3 to Day 30 \\
\hline 1 & $\$ 2.02$ & $\$ 0.00$ & $\$ 0.00$ \\
\hline 2 & $\$ 1.92$ & $\$ 0.00$ & $\$ 0.00$ \\
\hline 3 & $\$ 1.75$ & $\$ 5.64$ & $\$ 0.00$ \\
\hline 4 & $\$ 1.78$ & $\$ 0.00$ & $\$ 0.00$ \\
\hline 5 & $\$ 1.73$ & $\$ 3.46$ & $\$ 0.00$ \\
\hline 6 & $\$ 1.92$ & $\$ 0.00$ & $\$ 0.00$ \\
\hline 7 & $\$ 1.80$ & $\$ 0.00$ & $\$ 0.00$ \\
\hline 8 & $\$ 1.75$ & $\$ 0.00$ & $\$ 0.00$ \\
\hline 9 & $\$ 1.72$ & $\$ 6.28$ & $\$ 0.00$ \\
\hline 10 & $\$ 5.78$ & $\$ 2.13$ & $\$ 5.78$ \\
\hline 11 & $\$ 5.29$ & $\$ 1.45$ & $\$ 5.29$ \\
\hline 12 & $\$ 0.00$ & $\$ 0.00$ & $\$ 0.00$ \\
\hline 13 & $\$ 0.00$ & $\$ 0.00$ & $\$ 0.00$ \\
\hline 14 & $\$ 0.00$ & $\$ 5.11$ & $\$ 0.00$ \\
\hline 15 & $\$ 5.03$ & $\$ 1.31$ & $\$ 5.03$ \\
\hline 16 & $\$ 5.29$ & $\$ 1.38$ & $\$ 5.29$ \\
\hline 17 & $\$ 5.59$ & $\$ 1.46$ & $\$ 3.51$ \\
\hline 18 & $\$ 5.73$ & $\$ 1.49$ & $\$ 1.49$ \\
\hline 19 & $\$ 5.70$ & $\$ 1.49$ & $\$ 1.49$ \\
\hline 20 & $\$ 6.06$ & $\$ 1.58$ & $\$ 1.58$ \\
\hline 21 & $\$ 0.00$ & $\$ 1.62$ & $\$ 0.00$ \\
\hline 22 & $\$ 0.00$ & $\$ 1.62$ & $\$ 0.00$ \\
\hline 23 & $\$ 0.00$ & $\$ 1.62$ & $\$ 0.00$ \\
\hline 24 & $\$ 6.03$ & $\$ 1.57$ & $\$ 6.03$ \\
\hline 25 & $\$ 6.01$ & $\$ 1.57$ & $\$ 1.82$ \\
\hline 26 & $\$ 0.00$ & $\$ 1.61$ & $\$ 0.00$ \\
\hline 27 & $\$ 0.00$ & $\$ 0.00$ & $\$ 0.00$ \\
\hline 28 & $\$ 0.00$ & $\$ 0.00$ & $\$ 0.00$ \\
\hline 29 & $\$ 0.00$ & $\$ 0.00$ & $\$ 0.00$ \\
\hline 30 & $\$ 0.00$ & $\$ 0.00$ & $\$ 0.00$ \\
\hline 31 & $\$ 0.00$ & $\$ 0.00$ & $\$ 0.00$ \\
\hline 32 & $\$ 0.00$ & $\$ 0.00$ & $\$ 0.00$ \\
\hline 33 & $\$ 0.00$ & $\$ 6.26$ & $\$ 0.00$ \\
\hline 34 & $\$ 0.00$ & $\$ 6.18$ & $\$ 0.00$ \\
\hline 35 & $\$ 6.00$ & $\$ 2.07$ & $\$ 6.00$ \\
\hline 36 & $\$ 5.68$ & $\$ 1.48$ & $\$ 5.68$ \\
\hline 37 & $\$ 5.58$ & $\$ 1.45$ & $\$ 5.58$ \\
\hline 38 & $\$ 5.70$ & $\$ 1.48$ & $\$ 2.20$ \\
\hline 39 & $\$ 6.21$ & $\$ 1.70$ & $\$ 1.70$ \\
\hline 40 & $\$ 0.00$ & $\$ 1.73$ & $\$ 0.00$ \\
\hline 41 & $\$ 0.00$ & $\$ 1.74$ & $\$ 0.00$ \\
\hline 42 & $\$ 5.81$ & $\$ 1.59$ & $\$ 4.77$ \\
\hline 43 & $\$ 6.03$ & $\$ 1.65$ & $\$ 1.65$ \\
\hline 44 & $\$ 5.81$ & $\$ 1.59$ & $\$ 1.59$ \\
\hline 45 & $\$ 5.52$ & $\$ 1.51$ & $\$ 1.51$ \\
\hline 46 & $\$ 5.35$ & $\$ 1.47$ & $\$ 1.47$ \\
\hline 47 & $\$ 5.16$ & $\$ 1.41$ & $\$ 1.41$ \\
\hline 48 & $\$ 5.04$ & $\$ 1.38$ & $\$ 1.38$ \\
\hline
\end{tabular}


Table VI shows the per period results for cheap set point. It shows detail of the cheap set point pricing for each periods.

TABLE VI

SIMULATION RESULTS FOR PERIODS USING CHEAP SETPOINT

\begin{tabular}{|c|c|c|c|}
\hline \multicolumn{4}{|c|}{ Using Cheap as a set point } \\
\hline Period & Day 1 & Day 2 & Day 3 to Day 30 \\
\hline 1 & $\$ 2.02$ & $\$ 0.00$ & $\$ 0.00$ \\
\hline 2 & $\$ 1.92$ & $\$ 0.00$ & $\$ 0.00$ \\
\hline 3 & $\$ 1.75$ & $\$ 0.00$ & $\$ 0.00$ \\
\hline 4 & $\$ 1.78$ & $\$ 0.00$ & $\$ 0.00$ \\
\hline 5 & $\$ 1.73$ & $\$ 0.00$ & $\$ 0.00$ \\
\hline 6 & $\$ 1.92$ & $\$ 0.00$ & $\$ 0.00$ \\
\hline 7 & $\$ 1.80$ & $\$ 0.00$ & $\$ 0.00$ \\
\hline 8 & $\$ 1.75$ & $\$ 0.00$ & $\$ 0.00$ \\
\hline 9 & $\$ 1.72$ & $\$ 0.00$ & $\$ 0.00$ \\
\hline 10 & $\$ 5.78$ & $\$ 5.78$ & $\$ 5.78$ \\
\hline 11 & $\$ 5.29$ & $\$ 5.29$ & $\$ 5.29$ \\
\hline 12 & $\$ 0.00$ & $\$ 0.00$ & $\$ 0.00$ \\
\hline 13 & $\$ 0.00$ & $\$ 0.00$ & $\$ 0.00$ \\
\hline 14 & $\$ 0.00$ & $\$ 0.00$ & $\$ 0.00$ \\
\hline 15 & $\$ 5.03$ & $\$ 5.03$ & $\$ 5.03$ \\
\hline 16 & $\$ 5.29$ & $\$ 5.29$ & $\$ 5.29$ \\
\hline 17 & $\$ 5.59$ & $\$ 5.59$ & $\$ 5.59$ \\
\hline 18 & $\$ 0.00$ & $\$ 0.00$ & $\$ 0.00$ \\
\hline 19 & $\$ 5.70$ & $\$ 5.70$ & $\$ 5.70$ \\
\hline 20 & $\$ 0.00$ & $\$ 0.00$ & $\$ 0.00$ \\
\hline 21 & $\$ 0.00$ & $\$ 0.00$ & $\$ 0.00$ \\
\hline 22 & $\$ 0.00$ & $\$ 0.00$ & $\$ 0.00$ \\
\hline 23 & $\$ 0.00$ & $\$ 0.00$ & $\$ 0.00$ \\
\hline 24 & $\$ 0.00$ & $\$ 0.00$ & $\$ 0.00$ \\
\hline 25 & $\$ 0.00$ & $\$ 0.00$ & $\$ 0.00$ \\
\hline 26 & $\$ 0.00$ & $\$ 0.00$ & $\$ 0.00$ \\
\hline 27 & $\$ 0.00$ & $\$ 0.00$ & $\$ 0.00$ \\
\hline 28 & $\$ 0.00$ & $\$ 0.00$ & $\$ 0.00$ \\
\hline 29 & $\$ 0.00$ & $\$ 0.00$ & $\$ 0.00$ \\
\hline 30 & $\$ 0.00$ & $\$ 0.00$ & $\$ 0.00$ \\
\hline 31 & $\$ 0.00$ & $\$ 0.00$ & $\$ 0.00$ \\
\hline 32 & $\$ 0.19$ & $\$ 0.00$ & $\$ 0.00$ \\
\hline 33 & $\$ 1.63$ & $\$ 0.00$ & $\$ 0.00$ \\
\hline 34 & $\$ 1.61$ & $\$ 0.00$ & $\$ 0.00$ \\
\hline 35 & $\$ 1.56$ & $\$ 0.00$ & $\$ 0.00$ \\
\hline 36 & $\$ 5.68$ & $\$ 5.68$ & $\$ 5.68$ \\
\hline 37 & $\$ 5.58$ & $\$ 5.58$ & $\$ 5.58$ \\
\hline 38 & $\$ 5.70$ & $\$ 5.70$ & $\$ 5.70$ \\
\hline 39 & $\$ 0.00$ & $\$ 0.00$ & $\$ 0.00$ \\
\hline 40 & $\$ 0.00$ & $\$ 0.00$ & $\$ 0.00$ \\
\hline 41 & $\$ 0.00$ & $\$ 0.00$ & $\$ 0.00$ \\
\hline 42 & $\$ 0.00$ & $\$ 0.00$ & $\$ 0.00$ \\
\hline 43 & $\$ 0.00$ & $\$ 0.00$ & $\$ 0.00$ \\
\hline 44 & $\$ 0.00$ & $\$ 0.00$ & $\$ 0.00$ \\
\hline 45 & $\$ 5.52$ & $\$ 5.52$ & $\$ 5.52$ \\
\hline 46 & $\$ 5.35$ & $\$ 5.35$ & $\$ 5.35$ \\
\hline 47 & $\$ 5.16$ & $\$ 5.16$ & $\$ 5.16$ \\
\hline 48 & $\$ 5.04$ & $\$ 5.04$ & $\$ 5.04$ \\
\hline
\end{tabular}

The HDB non-contestable and contestable prices were constant at $\$ 5.11$ and $\$ 1.65$ throughout the periods.

\section{B. Housing Development Building Management System (HDBMS) Multi-Agent System (MAS) communications}

This sections shows the Multi-Agent System (MAS) communications results for Housing Development Building Management System (HDBMS).

Fig.13 shows the integration of the Multi-Agent System (MAS) with the Housing Development Building Management System (HDBMS) calculations. This integration shows the potential of a enhanced completed system for real life application.

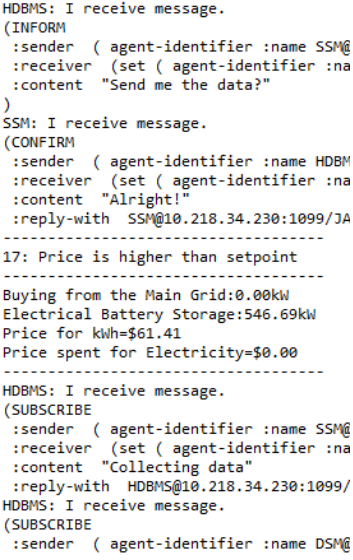

Fig. 13. MAS with HDBMS

Fig.14 shows the overall communication of the MultiAgent System (MAS) for HDBMS using JADE. It shows the importance of the interactions in the communication based network.

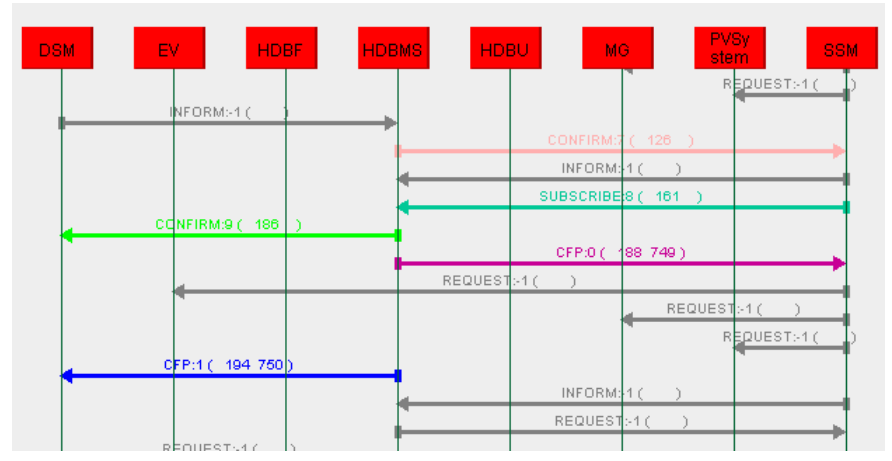

Fig. 14. Overall MAS communication

\section{Discussions}

Between contestable and non-contestable pricing, it shows significant difference of cost even when no system is implemented. After the system was implemented, it shows further reduction in cost with the set points methods. Although initially the set points method cost more but as the time increases, it shows slight difference with the average point system and a bigger difference with cheap set point by comparing the electricity cost of household.

At the same time, the per period simulations shows the system cost higher at later periods. This was due to "off-peak" prices availiable at later timings. However, it does not affect the overall results as it is implemented and compared with different methods.

These results concluded that with the Housing Development Building Management System (HDBMS) implemention, residential buildings were able to save a significant amount of electricity bills and reduce the load of electricity generators in the grid. HDBMS provides a more cost efficient way of using electricity. 


\section{Conclusions}

In this paper, the development of a smart building concept was designed to optimize the electricity usage through a Housing Development Building Management System (HDBMS). This system aims to optimize the energy efficiency and electricity costs of the residential buildings. A universal idea of a HDBMS for smart buildings was introduced by integrating Demand Side Management (DSM) and Supply Side Management (SSM) system. Multi-Agent System (MAS) was used to illustrate the communication process of agents between management systems and devices for the calculation and data of energy sources. Such system has shown its capabilities to achieve the optimal use of energy efficiency and electricity bills.

Enhancements of such smart grid techniques would only benefit the power grid in terms of increased dependability and software improvement for the grid. A less costly electricity bill could also be achieved with the help of renewable energy resources and electricity market. Eventually, this methodology would genuinely be a step closer towards a reliable and decentralized decision making smart building system via effective optimization system.

\section{REFERENCES}

[1] B. Asare-Bediako, P. F. Ribeiro, and W. L. Kling, "Integrated energy optimization with smart home energy management systems," in Innovative Smart Grid Technologies (ISGT Europe), 2012 3rd IEEE PES International Conference and Exhibition on. IEEE, 2012, pp. 1-8.

[2] J. Byun, I. Hong, B. Kang, and S. Park, "A smart energy distribution and management system for renewable energy distribution and context-aware services based on user patterns and load forecasting," IEEE Transactions on Consumer Electronics, vol. 57, no. 2, 2011.

[3] H.-L. Chao, C.-C. Tsai, P.-A. Hsiung, I. Chou et al., "Smart grid as a service: a discussion on design issues," The Scientific World Journal, vol. 2014, 2014

[4] D. D. Gross, "Spotlight on singapore: Smart grid city," 2010. [Online]. Available: http://www.cleantechinvestor.com/portal/smart-grid/ 5860-spotlight-on-singapore-smart-grid-city.html

[5] L. Hurtado, P. Nguyen, and W. Kling, "Agent-based control for building energy management in the smart grid framework," pp. 1-6, 2014.

[6] A. Mishra, D. Irwin, P. Shenoy, J. Kurose, and T. Zhu, "Greencharge: Managing renewableenergy in smart buildings," IEEE Journal on Selected Areas in Communications, vol. 31, no. 7, pp. 1281-1293, 2013.

[7] F. Corno and F. Razzak, "Intelligent energy optimization for user intelligible goals in smart home environments," IEEE Transactions on Smart Grid, vol. 3, no. 4, pp. 2128-2135, 2012.

[8] C. Wang, Y. Zhou, B. Jiao, Y. Wang, W. Liu, and D. Wang, "Robust optimization for load scheduling of a smart home with photovoltaic system," Energy Conversion and Management, vol. 102, pp. 247-257, 2015.

[9] C. Chen, K. Nagananda, G. Xiong, S. Kishore, and L. V. Snyder, "A communication-based appliance scheduling scheme for consumerpremise energy management systems," IEEE Transactions on smart Grid, vol. 4, no. 1, pp. 56-65, 2013.

[10] E. Mocanu, K. O. Aduda, P. H. Nguyen, G. Boxem, W. Zeiler, M. Gibescu, and W. L. Kling, "Optimizing the energy exchange between the smart grid and building systems," pp. 1-6, 2014.

[11] P. Zhao, S. Suryanarayanan, and M. G. Simões, "An energy management system for building structures using a multi-agent decision-making control methodology," IEEE Transactions on Industry Applications, vol. 49, no. 1, pp. 322-330, 2013.

[12] S. D. McArthur, E. M. Davidson, V. M. Catterson, A. L. Dimeas, N. D. Hatziargyriou, F. Ponci, and T. Funabashi, "Multi-agent systems for power engineering applicationspart i: Concepts, approaches, and technical challenges," pp. 1743-1752, 2007.

[13] S. D. McArthur, E. M. Davidson, V. M. Catterson, A. L. Dimeas, N. D. Hatziargyriou, F. Ponci, and T. Funabashi, "Multi-agent systems for power engineering applicationspart ii: Technologies, standards, and tools for building multi-agent systems," pp. 1753-1759, 2007.
[14] W. Li, T. Logenthiran, V.-T. Phan, and W. L. Woo, "Intelligent multiagent system for power grid communication," in Region 10 Conference (TENCON), 2016 IEEE. IEEE, 2016, pp. 3386-3389.

[15] W. Li, T. Logenthiran, W. Woo, V. Phan, and D. Srinivasan, "Implementation of demand side management of a smart home using multi-agent system," in IEEE World Congress on Computational Intelligence. IEEE, 2016, pp. 1-8.

[16] W. Li, T. Logenthiran, and W. Woo, "Intelligent multi-agent system for smart home energy management," in Smart Grid Technologies-Asia (ISGT ASIA), 2015 IEEE Innovative. IEEE, 2015, pp. 1-6.

[17] W. Li, T. Logenthiran, V.-T. Phan, and W. L. Woo, "Intelligent housing development building management system (hdbms) for optimized electricity bills," in Environment and Electrical Engineering and 2017 IEEE Industrial and Commercial Power Systems Europe (EEEIC/I\&CPS Europe), 2017 IEEE International Conference on. IEEE, 2017, pp. 1-6.

[18] B. Nee, "Singapore energy statistics 2015," 2015. [Online]. Available: https://www.ema.gov.sg/cmsmedia/Publications_and_ Statistics/Publications/SES2015_Final_website_2mb.pdf

[19] E. M. Authority, "Energy consumption," 2015. [Online]. Available: https://www.ema.gov.sg/cmsmedia/Publications_and_ Statistics/Publications/ses/2015/energy

[20] P. E. Centre, "Energy audit of selected hdb," 2004. [Online]. Available: http://www.siongboon.com/projects/2010-08-22\% 20electronic $\% 20$ ballast/Energy $\% 20$ Audit $\% 20$ of $\% 20$ selected $\% 20 \mathrm{HDB} \%$ 20residential\%20blocks\%20in\%20Singapore\%20Aug\%202004.pdf

[21] teoalida, 2015. [Online]. Available: http://www.teoalida.com/singapore/ hdbstatistics/

[22] Mypower, "Overview of the singapore electricity market," 2014 [Online]. Available: https://www.mypower.com.sg/About/about.html

[23] E.M.Company, "Price information," 2015. [Online]. Available: https: //www.emcsg.com/marketdata/priceinformation \\#priceDataView

[24] S.P.Ltd, “Tariffs," 2014. [Online]. Available: http://www. singaporepower.com.sg/irj/servlet/prt/portal/prtroot

[25] J. LUTHER, "Solar energy technology primer: A summary," 2011.

[26] L. T. Authority, "Factsheet on electric vehicles," 2010. [Online]. Available: http://www.lta.gov.sg/data/apps/news/press/2010/ EV\%20Factsheet\%20.pdf

[27] K. Mahbubani, "Big idea no. 1: A 'less-car' singapore," 2014. [Online]. Available: http://www.straitstimes.com/opinion/ big-idea-no-1-a-less-car-singapore 